\title{
A acessibilidade à informação no espaço digital
}

\section{Elisabeth Fátima Torres}

Doutora em Engenharia - UFSC

RexLab, U niversidade Federal de Santa C atarina

eftorres@terra.com.br

\section{Alberto A ngel M azzoni}

M estre em M atemática A plicada - U nicamp,

D epartamento de Informática, U niversidade Estadual de M aringá

João Bosco da M ota Alves

D outor em Engenharia - UFRJ,

D epartamento de Informática e Estatística, U FSC

\section{Resumo}

O trabalho aborda aspectos referentes à acessibilidade no espaço digital. Uma ênfase especial é dada às situações relacionadas à interação das pessoas portadoras de deficiência com a informação, em ambientes de bibliotecas. $O$ texto propõe algumas adequações para a acessibilidade ao espaço digital, conforme categorias de usuários, com o intuito de contribuir para um maior nível de acessibilidade à informação, nesse espaço.

\section{Palavras-chave}

Acessibilidade; Espaço digital; Bibliotecas; Pessoas portadoras de deficiência; Ajudas técnicas.

The accessibility to the information in the digital space

\begin{abstract}
The work approaches aspects concerning to the accessibility in the digital space. A special emphasis is given to the situations related to the persons with disabilities and their interaction with the information, in libraries's environment. The text proposes some adaptations for the accessibility to the digital space, according to users' categories and has the intention of contributing for a larger accessibility level to the information, in that space.
\end{abstract}

\section{Keywords}

Accessibility; Digital space; Library People with disabilities; Technical aids.

\section{INTRO DUÇÃO}

A acessibilidade éum processo dinâmico, associado não só ao desenvolvimento tecnológico, mas principalmente ao desenvolvimento da sociedade. A presenta-seem estágios distintos, variando de uma sociedade para a outra, conforme seja a atenção dispensada à diversidade humana, por essa sociedade, àépoca.

A acessibilidadeé um conceito que envolvetanto aspectos do espaço físico, o espaço em que vivemos, como do espaço digital. A legislação brasileira* conceitua acessibilidade como sendo a possibilidade e condição de alcance para utilização, com segurança e autonomia, dos espaços, mobiliários e equipamentos urbanos, das edificações, dos transportes e dos sistemas e meios de comunicação por pessoa portadora dedeficiênciaou com mobilidadereduzida.

A s primeiras batal has e conquistas do movimento próacessibilidadeforam referentes ao espaço físico, tais como os projetos livres de barreiras e a inclusão da satisfação do usuário com a usabilidade do produto, no ciclo dos projetos dos produtos. Embora não sepossaconsiderar que a acessibilidade já tenha sido al cançada, no espaço físico, particularmentena sociedade brasileira, os movimentos pró-acessibilidade seguem avançando, eatualmente consta, entre seus objetivos, alcançar aacessibilidadeno espaço digital, o espaço das comunicações via computador.

A s possibilidades que estenovo espaço, o espaço digital, criado pelas tecnologias de informação ecomunicação, traz para 0 atendimento às distintas formas de interação das pessoas com a informação, respeitando as suas preferências elimitações, tanto aquel as relacionadas aos equipamentos utilizados, quanto às limitações orgânicas, são apresentadas, ao longo do artigo. A tenção especial édada à discussão sobre arelação existente entre as bibliotecas e a acessibilidade no espaço digital, apresentando-se al gumas adequações para a acessibilidade que podem e devem ser adotadas nos serviços prestados pelas bibliotecas.

\footnotetext{
${ }^{*}$ Lei 10.098 , de 19 de dezembro de 2000.
} 


\section{Elisabeth Fátima Torres/ A lberto A ngel Mazzoni / João B osco da M ota A lves}

\section{O ESPAÇO DIG ITAL}

O espaço digital podeser considerado como um outro espaço. Embora penetre no espaço tridimensional (3D) em que vivemos, possui propriedades intrínsecas a ele, queo caracterizam como um espaço distinto do espaço $3 \mathrm{D}$ no qual estamos imersos. C onforme $\mathrm{D}$ e L as $\mathrm{H}$ eras (2000), éimportante observar queo espaço digital não é um espelho do espaço tridimensional, embora, a princípio, por inércia, hajauma "tendência" a se repetir nele o que sefaz no 3D, eassim se passam para ele os arquivos, os livros, os filmes, a música etc. D a análise queesse autor apresenta sobreas propriedades do espaço digital destacamos:

- densidade - o espaço digital é denso, mas não sofre saturação. O u seja, possui uma alta capacidade de armazenamento deinformações, mas não se satura, pois sempreé possível estender-se esse espaço, o que ocorre, por exemplo, toda vez que se cria um novo sítio web, ou um material multimídia em CD .

- ubiqüidade - uma mesma informação está em lugares distintos;

- deslocação - épossível deslocar-serapidamenteneste espaço, deum endereço em U RL ${ }^{*}$, por exemplo, passase facilmente a outro, em qualquer ponto daweb;

- hipertextualidade - o texto obedece a uma nova geometria, sem a necessidade de páginas, e são as palavras que vão abrindo o texto, à medida que sefixa a atenção nelas eque são utilizadas para abrir novas conexões.

A presença desse novo espaço já foi incorporada em vários modelos teóricos, desenvolvidos por autores de renome internacional. Echeverria (2001) referencia vários desses autores erelaciona entre esses os trabal hos deM cL uhan (aldeia gl obal), Töffler (terceira onda), G ore (ciberespaço, autopistasda informação), informeBangemann (sociedade da informação), Barlow (nova fronteira eletrônica), $\mathrm{N}$ egroponte (mundo digital), D eK erckhove (mentes interconectadas), Lévy ( mundo virtual), C astells ( sociedade rede), U nião Européia 2000 (espaço eletrônico) etc.
A esse conjunto de expressões jáutilizadas como referências ao espaço digital, Echeverria (2001) acrescenta mais uma e propõe o termo terceiro entorno ${ }^{* *}(E 3)$, referindo-se a um novo espaço-tempo no qual os seres humanos se desenvolvem (no sentido individual, comunitário, lingüístico etc.). E são as novas tecnologias da informação e das comunicações (TIC) quepossibilitam a construção desse novo espaço-tempo social. Esseautor considera sete tecnologias como sendo as construtoras do E 3: o telefone, a televisão (radiotelevisão), o dinheiro el etrônico, as redes telemáticas (tipo I nternet ou de outros tipos), as tecnologias multimídia (discos duros, cd-rom, D VD etc.), os videojogos eas tecnologias de realidadevirtual.

D evido a essas características, peculiares ao espaço digital, tem havido uma forte tendência a se levar para elea maior parte dos documentos einformações importantes, sendo este, atualmente, o espaço original em que são produzidos os novos documentos e, para o qual, são transferidas todas as informações recuperadas, em obras raras e outros documentos importantes, anteriormente existentes apenas em suportes não-digitais como o papel, o papiro, as telas etc. Para D e L as H eras (2000), isso ocorre porque o espaço digital exerce um forte efeito atrator sobre o espaço tridimensional epor isso vão surgindo as versões digitais das escolas, das empresas, das bibliotecas, dos fóruns, das reuniões, dos bate-papos, dos jogos, dos livros, das músicas etc. N ão se pode, contudo, esquecer que esteespaço permite não apenas a reprodução do quesefaz no espaço tridimensional, mas também permite a criação do "novo", daquilo que ainda não foi possível sefazer no espaço tridimensional. Construir a acessibilidade à informação éuma dessas possibilidades ainda não al cançada.

\section{O DESENHO PARA TO DO SNO ESPAÇO DIGITAL}

Embora pareça contraditório, pode-se afirmar que as barreiras arquitetônicas não são o maior obstáculo enfrentado pelaspessoas portadoras dedeficiência. 0 maior obstáculo está no acesso à informação e, conseqüentemente, a aspectos importantes relacionados à informação, como a educação, o trabal ho eo lazer. A preocupação atual dos defensores da acessibilidade está em garantir que esses princípios sejam observados também no espaço digital, o espaço da informática e das comunicações. A Internet tem sido muito usada para exemplificar

\footnotetext{
** Para o autor citado, o E1 refere-se ao entorno rural, à sociedade agrária, e 0 E2, ao entorno urbano, à sociedade industrial, embora tanto em E1 como em E2 outras modalidades de organização social também possam ser observadas.
} 


\section{A acessibilidade à informação no espaço digital}

esse conceito, por conter aspectosfundamentais deambas astecnologias.

U mal nternet acessível implica que ela esteja disponível às pessoas, tanto no aspecto financeiro quanto no formato, ou na mídia, em queas informações são divulgadas. A flexibilização da apresentação da informação em formas distintas, queapresentem correspondência em termos de conteúdo, deve ser considerada, tanto como uma questão de necessidade, como de preferência de al guns usuários. A necessidadepodese manifestar pelaimpossibilidade de aceder à informação divulgada deumaúnica forma, sempreque essa forma setorna inacessível, seja devido às características técnicas dos equipamentos dos usuários (qualidade ecusto das tecnologias utilizadas), ou pelas características corporais dessas pessoas (por exemplo: deficiências sensoriais, problemas de coordenação motora etc.) . A preferênciasemanifesta quando os usuários optam por ter o acesso àinformação através da mídia que mais Ihes convém, ou mais I hes agrada, conformeseja o seu estilo de aprendizagem.

Embora não existam, ainda, mecanismos intergovernamentais que promovam a acessibilidade dos conteúdos disponibilizados via I nternet, al guns países vêm adotando políticas nesse sentido, particularmente no que diz respeito aos sítios web de suas repartições públicas. A ustrália, C anadá, Estados U nidos e Portugal seencontram entre os países pioneiros a adotar políticas nesse sentido.

Esforço internacional notável, pró-acessibilidadeno espaço digital, tem sido feito pelo $\mathrm{W} 3 \mathrm{C}^{*}$, queatua como gestor de diretivas paraal nternet. F oram definidas, por esse comitêinternacional, al gumas recomendações para a construção de páginasw eb, aplicáveis também a outros documentos disponibilizados no espaço digital, que podem ser resumidas por meio da adoção desses princípios:

- Assegurar uma transformação harmoniosa da informação - A presente a informação de mais de uma maneira. Por exemplo: o quefor áudio deveter uma versão em texto; o quefor imagem deveser descrito. Esteprincípio se justifica tanto em função de possíveis limitações dos usuários quanto da existência de tecnologias dequalidades distintas.

- Fazer o conteúdo compreensível enavegável - U seum estilo bem simples, observea estruturalógica do documento, em termos da compreensão dos seus diversos pontos

\footnotetext{
${ }^{*}$ W $3 C$ - World Wide Web Consortium

http://www.w3.org/WA I

Ci. Inf., Brasília, v. 31, n. 3, p. 83-91, set./dez. 2002
}

de enlace. 0 usuário podeter dificuldades em compreender a informação, seja devido ao idioma, seja devido ao contexto em queela é apresentada.

D eve-selembrar quetodas as propostas apresentadas no sentido de obter a acessibilidade na I nternet são aplicáveis também a outros textos edocumentos de interesse público, disponibilizados nas bibliotecas em outros suportes digitais, como cd-rom, disquete, DVD etc.

A não-observância daacessibilidade no espaço digital pelos autores dos materiais disponibilizados nessa forma pode ser considerada como uma discriminação feita a milhares de usuários, quantidade essa que se torna não mensurável quando essa informação apareceem sítios web deacesso livre. A lutapor sítiosweb acessíveis está incluída entre as exigências por igual dade de condições, conduzidas pelos movimentos das pessoas com limitações oriundas de deficiências, nos países em queo processo de informatização da sociedadeestámais avançado.

\section{ACESSIBILIDADE N O ESPAÇ O DIG ITAL}

A acessibilidade no espaço digital consiste em tornar disponível ao usuário, deformaautônoma, todaainformação quelhefor franqueável (informação para aqual o usuário tenha código de acesso ou, então, estejaliberada paratodos os usuários), independentemente de suas características corporais, sem prejuízos quanto ao conteúdo da informação. E ssa acessibilidade é obtida combinando-se aapresentação da informação deformas múltiplas, sejaatravés de uma simples redundância, seja através deum sistema automático de transcrição de mídias, com o uso deajudas técnicas (sistemas de leitura de tela, sistemas de reconhecimento dafala, simuladores de teclado etc.) que maximizam as habilidades dos usuários que possuem limitações associadas a deficiências.

C omo o espaço digital seestende por todo o espectro das comunicações, viatelevisão digital, computadores e redes telemáticas, éeste o espaço no qual o direito àinformação, de uma forma acessível, deve ser reivindicado e desenvolvido.

Existem níveis distintos de obstáculos para a acessibilidade digital. Romañach (2002) faz umaanalogia com os obstáculos criados pelas escadas no espaço físico e consideraa existência detrês distintos degraus. Parase alcançar essa acessibilidade, é necessário superar os obstáculos correspondentes aos seguintes degraus: 
- degrau 1 - Poder acionar os terminais de acesso àinformação: telefones, computadores, caixas de auto-atendimento bancário, quiosques virtuais etc.

- degrau 2 - Poder interagir com os elementos dainterface humano-máquina tais como os menus de seleção, botões lógicos, sistemas de validação etc.

- degrau 3 - Poder aceder aos conteúdos que são disponibilizados nos terminais, sejam informação financeira, lúdica, geral, vídeos, imagens, áudio etc.

A ssociada à acessibilidade dos sítios w eb existem formas de verificar e certificar a qualidade dessas páginas. São apresentados, como exemplo, o selo de certificação do $B O B B Y$, o pioneiro nesse tema, eo selo do $W 3 C$, considerado, atualmente, como o mais completo e disponibilizado em três graus distintos de qualidade.

A preocupação com aacessibilidade digital estápresente nas políticas públicas de informatização, em muitos países, edeverá, necessariamente, estar presente, quando se pensar em uma sociedade da informação para todos.

\section{A s ajudas técnicas informáticas e sua contribuição para 0 acesso à informação e a construção do conheci- mento}

Q ual éo espaço ocupado pelo ser humano? H ojeseaceita o ser humano também como um ser social, éindivíduo e é parte de um organismo maior, constituído pelas demais pessoas com as quais convive. $E$, como indivíduo, quais são as fronteiras do seu ser? Essa é umaquestão quetem ocupado os filósofos, como G eorges C anguilhen (1995, p. 162),

"[...] o homem, mesmo sob o aspecto físico, não selimita a seu organismo. 0 homem, tendo prolongado seus órgãos por meio de instrumentos, considera seu corpo apenas como um meio detodos os meios deação possíveis."

Essa extensão do ser humano, por meio de instrumentos éainda mais evidenciada para as pessoas portadoras de deficiência, ese efetiva com ajudas técnicas. C onsideraseajuda técnica qualquer produto, instrumento, equipamento ou sistematécnico utilizado por uma pessoa com limitações oriundas de deficiência, fabricado especificamenteou disponível no mercado, criado para prevenir, compensar, mitigar ou neutral izar a deficiência, incapacidade ou menusvalia dessa pessoa. Essa definição foi adotada pela $\mathrm{O}$ rganização I nternacional de $\mathrm{N}$ ormalização, em sual SO 9999.
FIGURA 1

Selos que comprovam a acessibilidade de páginasweb

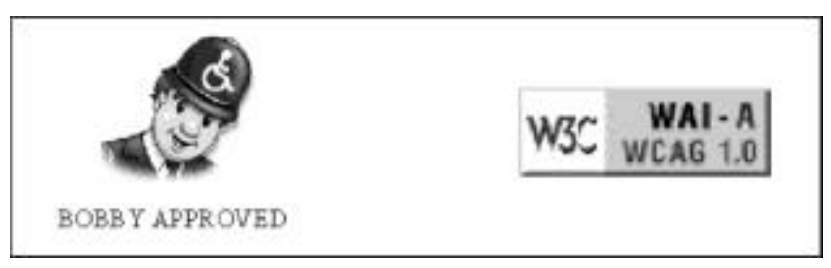

U matecnologia, embora possater a sua concepção motivada por determinada categoria de deficiência, depois de criadatem as possibilidades de sua utilização ampliadas. $\mathrm{H}$ á pouco tempo, seria inconcebível pensar queuma pessoa surda poderia usar, sem intermediários, um aparel ho de tel efone para se comunicar. H oje, esta facilidade já estádisponível para os usuários detelefones celulares de mensagem.

U ma outra tecnologia que atende a distintas categorias de usuários são os programas de reconhecimento dafala. Embora estatecnologia esteja sen do aperfeiçoada, vários produtos jáestão sendo comercial izados. Entreos seus possíveisusuários, estão pessoas com deficiência de coordenação motora para digitar, pessoas com deficiência visual equalquer pessoaque prefiraditar em vez dedigitar. F alta al guém nesta relação? Sim, estão faltando os surdos que dominam a técnica da oralidade, que podem utilizar este produto simplesmentecomo as demais pessoas (que pensam queémais prático ditar do que digitar) e podem, também, encontrar neste produto uma outra finalidade, utilizando-o como umaforma de exercitar eaperfeiçoar a sua oralidade.

Por isso, emborana prática do dia-a-dia primeiro estejaa pessoacom comprometimentos no desempenho dedeterminadas atividades, eseja a partir daí que surge amotivação para pesquisar por ajudas técnicas adequadas a essa pessoa, as categorizações, conforme Sanchez M ontoya (1999), são mais bem apresentadas a partir da descrição da contribuição feita por essa tecnologia. É a partir daí que seanalisa se haverá ou não benefícios para as pessoas com deficiência visual, para as com deficiênciaauditiva, paraas com deficiência de motricidade, para as com deficiênciacognitiva ou, atémesmo, para as pessoas sem deficiência.

Q uando se analisaa presença da informática, em sistemas utilizados por pessoas portadoras de deficiência, é possível estabelecer algumas categorias. A presenta-se, a seguir, uma categorização das ajudas técnicas informáticas, conforme M azzoni \& T orres (2001). 


\section{A acessibilidade à informação no espaço digital}

N o âmbito daeducação, encontram-sesistemas de ajuda para:

- trabalhar com o computador - como dar instruções, compreender as ações executadas pela máquina, obter e anal isar as saídas, acessar os periféricos etc.;

- aprendizagem - aprender sobre ajudas técnicas específicas deinteressepróprio (como o uso deum sistema que faz a leitura detelas) , desenvolver a fala, aprender e desenvolver alíngua de sinais, conhecer alíngua de sinais de outros povos, aprender línguas e culturas de outros países, conhecimentos sobre Braille, fixar condutas esperadas, exercitar determinadas habilidades etc.;

- comunicar-sepor meio do computador - utilizar o computador como intermediário na conversa com outra pessoa, com ou sem deficiência, utilizando linguagens verbais ou linguagens não-verbais, como, por exemplo, os pictogramas;

N o âmbito mais geral, podem ser relacionados:

- Sistemas para M obilidade - auxiliam no deslocamento da pessoa, seja em casa ou na rua, permitindo deslocamentos com al gum grau de autonomia, como sistemas para reconhecimento el etrônico de referenciais espaciais, sistemas para acionamento de semáforos, dispositivos para anotações e veículos adaptados às características dos usuários, sistemas para identificação de conduções (ônibus etrens) conformea linha desejada;

- Sistemas para C ontrole do Entorno - facilidades tais como acender ou apagar as luzes, abrir portas, acionar os aparelhos domésticos, fazer ligações telefônicas para números selecionados etc.

D eve-se destacar que, se paraal gumas pessoas as ajudas técnicas atuam como complemento, permitindo que melhorem a forma como desempen ham as atividades, para outras elas são imprescindíveis, sendo por meio delas queseus intelectos conseguem seexpressar. Paraeste segundo grupo de pessoas, éa tecnologia queintermedia a sua comunicação com o mundo, tanto nas situações de educação como nas demais interações sociais.

É importanteter sempreem menteque nem tudo queé divulgado naforma digital vai ser recebido pelo usuário, se não foi pensado o aspecto da acessibilidadea essa informação, no momento em que se concebeu o conteúdo da mesma. Será que os conteúdos didáticos elaborados pelas equipes de desenvolvimento de cursos, com os recursos de multimídia propiciados pela informática, estão chegando ao nível de percepção de seus alunos? Para que servem uma foto sem a descrição e uma canção sem a letra, em um C D didático, por exemplo, para um al uno cego eum aluno surdo, respectivamente?

$\mathrm{H}$ oje, considera-seque o desenvolvimento de materiais didáticos de boa qualidade a serem utilizados em cursos conduzidos no espaço digital exige o envolvimento de uma equipe constituída por profissionais com distintas competências, tais como os autores responsáveis pelos conteúdos abordados, os construtores do ambiente do curso no qual ocorre a interação humano-computador, os desenvolvedores das opções em multimídia, os tutores, os monitores, os profissionais de suporte técnico responsáveis pela redee pel o banco de dados etc. $\mathrm{C}$ abea essa equipe de desenvolvimento, além dos conhecimentos referentes ao uso dos computadores (metodologiase demais conhecimentos técnicos) e das ajudas técnicas informáticas, preocupar-setambém com os conteúdos que estão sendo disponibilizados aos seus alunos, respeitando os estilos de aprendizagem eas possibilidades de percepção dos mesmos. A informação que não é divulgada, ou não podeser captada, deforma redundantenão é uma informação realmente acessível. A redundância é obtida quando se cuida para que haja um equivalente textual para os conteúdos divulgados por meio de imagens ou desons, ou seja, deve-se combinar o uso do som com o uso do texto e as imagens. Q uando usadas, seja em forma estática ou dinâmica, devem ter um correspondente textual.

A tualmente, existem ajudas técnicas que permitem transformar o texto escrito digitalizado em som, ejáexiste a possibilidade decaptar textos falados etransformá-los em texto escrito digitalizado, porém as imagens, sejam estáticas ou em movimento, necessitam de descrição para se obter um equivalentetextual para as mesmas.

\section{COMO CONSTRUIR A ACESSIBILIDADE, RE SPE IT A N D O AS LIM I T AC Õ ES A PRE SE NTADAS PELOS U SUÁRIOS}

Janik (1997) opina que mais queser um espaço privilegiado para o acesso à informação eà cultura, as bibliotecas desempenham um importante papel na integração das pessoas com limitações oriundas de deficiência, cabendo aos profissionais que atuam nas bibliotecas conhecer e saber atender às necessidades desses usuários, paraqueainformação desejada possa chegar a eles. Essa autora analisa a necessidade de que os serviços bibliotecários estejam atentos às necessidades peculiares de seus usuários afetados por deficiências. 


\section{Elisabeth Fátima Torres/ A lberto A ngel Mazzoni / João B osco da M ota A lves}

Para efeitos deste estudo sobreaacessibilidade no espaço digital, será desenvolvida a análise referente às adequações de acessibilidade necessárias para um correto atendimento ausuários com limitações associadas com a audição, a visão e a motricidade. A atenção a esse conjunto de requisitos deve ser considerada como imprescindível, ou como meta a ser alcançada, para todos os serviços disponibilizados pelas bibliotecas quejá atuam no espaço digital.

O susuários dos serviços de biblioteca podem chegar ao espaço digital, relacionado a essabiblioteca, de duas maneiras: de forma remota, acessando os serviços e acervo disponibilizado, via on-line, ou então deformapresencial, comparecendo à biblioteca e, a partir daí, acessando o acervo. Q uando o acesso à biblioteca ocorre de forma remota, os problemas deacessibilidadeque o usuário venha a enfrentar são de responsabilidade da biblioteca, no que diz respeito apenas ao segundo eterceiro degraus. C onformedefinidos por Romañach (2002), respectivamenteo ambiente deinteração com abibliotecae o acesso aos conteúdos disponibilizados. Q uando interage com 0 espaço digital, a partir da própria biblioteca, podem surgir também os obstáculos do primeiro degrau, que diz respeito a poder utilizar os equipamentos disponibilizados, os quais devem estar equipados com as ajudas técnicas adequadas, conformeseja anecessidade do usuário.

Para a elaboração das adequações de acessibilidade sugeridas aos responsáveis pelas bibliotecas, para meIhor atenção aos seus usuários com limitações oriundas de deficiência, demaneira aquenão tenham restringido o seu direito de acesso à informação, foi considerada a existência desses três degraus. Essas adequações dizem respeito tanto às ajudas técnicas a serem adquiridas pelas bibliotecas como também aos requisitos mínimos que devem ser solicitados aos desenvolvedores dos sistemas deinformação edocumentação destinados ao uso específico das bibliotecas, tais como acesso a bases de dados, consulta ao catálogo e acesso à biblioteca virtual.

\section{a) A dequações de acessi bilidade para usuários com limitações associadasà motricidade}

Visa a atender a usuários com problemas de coordenação motora emobilidade, seja devido a quadros de paralisia, a amputações, má-formação dos membros etc. $C$ abe destacar que essa categoria de usuários é a que requer mais atenção no que diz respeito à acessibilidade ao espaço físico, espaço no qual seencontram os equipamentos a serem utilizados, nainteração com o espaço digital.
- Independênciado uso do mouse, principalmentecomo dispositivo apontador. I sso pode ser obtido com outros dispositivos de mais fácil utilização pelo usuário, que atuem como acionadores do mouseou então por meio de comandos do teclado.

- Independência do uso do teclado, substituindo-o por simuladores do teclado via software, acionados por movimentos voluntários, tais como sopro, toques em acionadores, movimentos de cabeça etc.

- I ndependência do uso simultâneo devárias teclas. Essa possibilidade está disponível nos sistemas operacionais geralmente em uso nos computadores domésticos, devendo ser acionada se o usuário a necessitar.

- F lexibilidade no tempo de resposta, nainteração com o sistema. O s sistemas não podem, sob nenhum motivo, desconectar usuários que demoram a realizar os procedimentos. Essa lentidão deverá também ser considerada no caso deacesso a serviços que são pagos em função do período deutilização.

\section{b) A dequações de acessi bilidade para usuárioscom limitações associadasà audição}

Visa a aten der a usuários com baixa audição eaos surdos, sejam el es oralizados ou não. D eve-se observar que, entreesses usuários, nem todos secomunicam por meio de Libras*, queéa Língua Brasileira de Sinais.

- O s materiais audiovisuais devem estar legendados, preferentementetanto com legendas em texto como em Libras;

- O pções para controle do volume, no hardware disponibilizado pelabiblioteca para a utilização desses usuários;

- A cesso visual àinformação sonora (por meio datranscrição em equivalentes textuais ou pictóricos) e uma sinalização visual para os eventos do sistema em utilização (como estados do sistema, envio erecepção demensagens nal nternet etc.).

- Serviços para a transcrição em texto de documentos digitaisorais.

\footnotetext{
* Libras - Língua Brasileira de Sinais, reconhecida como língua oficial em 2002, por meio da Lei 10.436 .
} 


\section{A acessibilidade à informação no espaço digital}

\section{c) A dequações de acessi bilidade para usuários com limitações associadasà visão}

V isa a atender a usuários com baixa visão e aos cegos. D eve-se observar que, entre esses usuários, nem todos sabem ler em Braille.

- O pções para ampliação da imagem e modificação dos ef eitos de contraste na tela. I sso pode ser obtido, por exemplo, com o uso desoftware que faça a ampliação e também com navegadores de uso geral que permitam a modificação no tamanho das fontes usadas no texto.

- Independênciado uso do mousecomo apontador, com um uso maior do teclado. I sso exige que a estruturados documentos seja anal isada, sob o aspecto de como ocorre a seqüência de navegação pela mesma, quando se utilizam apenas os recursos do teclado.

- U so desoftware* paraleituradetela, ao qual estáassociado sintetizador de voz. Q uanto aos documentos a serem consultados, utilizando-se sistemas de leitura de tela, éimportanteque seja verificada a estrutura dos documentos, sob o aspecto do agrupamento das informações etambém sob a compreensão do significado dos elos, ou seja, o resultado queseráobtido quando se escoIha um caminho na navegação dentro dos hipertextos.

- O pção para o acesso sonoro à informação, seja ela texto, via arquivo em formato compatível com o sistema de leitura de tela em uso, ou imagem, por meio da utilização da transcrição das partes visuais dos documentos ( fotos, desenhos, mapas etc.), em equivalentes textuais.

- O pções parao acesso à informação em Braille, seja na forma detexto impresso, seja por intermédio do periférico linha Braille.

\section{A CONSTRU ÇÃO DE HIPERTEXTO SACESSÍVEIS E A TRANSCRIÇÃO DA INFO RMAÇÃO}

As possibilidades de utilização dos recursos multimídia trazem grandes contribuições para a produção de materiais didáticos digitais, permitindo o respeito ao ritmo de aprendizagem dos educandos, como também ao estilo de aprendizagem dos mesmos. C ontudo, énecessário lembrar que há um grupo importante de usuários com problemas de deslocamento, no plano físico, ede "navegação", no espaço digital, paraos quais o critério estético podeser um obstáculo. D eve-se considerar semprequea estéticanão precisa ser adversária daacessibilidade.

\footnotetext{
*A tualmente existem dois produtos brasileiros : D osvox e Virtual Vision.
}

0 fato de muitos autores didáticos se esquecerem das pessoas com limitações oriundas de deficiência estágerando prejuízos de conteúdo programático para esses educandos, em termos delivros, ealgo semelhante ocorre em termos do software. C uidado especial deve-se tomar com a elaboração de equivalentes textuais, paraas imagens eos sons.

Como podeum equivalentetextual tornar acessível uma imagem? A tenção especial deveser dada a estaquestão por todos os autores que trabal ham com amultimídia. O conteúdo textual podeser apresentado ao usuário sob a forma de discurso sintetizado, em Braille, ou ainda em texto visível. C ada um destes três processos faz apelo a um sentido diferente, permitindo assim queessas informações setornem acessíveis a grupos representativos de um vasto leque de limitações e deficiências etambém a pessoas que não possuem incapacidades orgânicas, mas dispõem detecnologia de qualidade distinta daquelaque o desenvolvedor do produto considera como padrão, tanto em termos do software como de equipamentos. Por exemplo, a maioria dos usuários domésticos, por motivosfinanceiros, opta por imprimir em preto em branco, ficando assim eles também beneficiados pela adoção da prática de construir um equivalentetextual para as imagens.

Paraser verdadeiramenteútil, o texto tem detransmitir amesmafunção ou finalidadequeaimagem ou som. Essa éuma das exigências para a acessibilidade de conteúdos digitais, conforme o W3C:

D iretiva 1 do W 3 C - F ornecer al ternativas ao conteúdo sonoro evisual.

Proporcionar conteúdo que, ao ser apresentado ao usuário, transmita, na essência, as mesmas funções efinalidade do que o conteúdo sonoro ou visual.

C omo se constrói um equivalentetextual? C onsidere o caso do equival entetextual de uma imagem fotográfica de uma paisagem de praia. Esse exemplo ajuda a compreender os conceitos envolvidos.

- Seafinalidade da imagem é, sobretudo, decorativa, um texto do tipo "F otografia da praia de Pasárgada" pode preencher afunção necessária.

- Já, se a finalidade da fotografia for ilustrar uma informação, bem determinada, acerca da geografia dessa região, o equivalente textual tem detransmitir essa informação. Por exemplo: “O bserva-senafoto queapraiaapresentauma baía, na qual estácontida uma grande ilha." 


\section{Elisabeth Fátima Torres/ A lberto A ngel Mazzoni / João B osco da M ota A lves}

- Se afotografiativer sido inseridano hipertexto para indicar ao usuário que ele deveselecionar aimagem (por exemplo, fazendo clique sobre ela), o equivalente textual poderá ser: "A cesse aqui as informações turísticas sobre Pasárgada".

C ada autor é o responsável pelos seus documentos disponibilizados no espaço digital (como artigos, dissertações e teses), devendo, portanto, cuidar para que os mesmos atendam aos critérios de acessibilidade.

\section{A RELAÇÃO ENTRE AS BIBLIOTECAS A A ACESSIBILIDADE NO ESPAÇ O DIGITAL}

C onforme anik (1997), nos dias atuais, nenhuma pessoa deve considerar que o acesso aos serviços de biblioteca sejaum luxo, não-prioritário, para os cidadãos com limitações oriundas de deficiência. Essa autoraopina que as bibliotecas, sobretudo as públicas, devem colocar à disposição detodas as pessoas, sem distinção de nível escolar ou intel ectual, os documentos de queelas necessitam, levando em consideração as suas capacidades pessoais e o ritmo conveniente a elas. Q uando discute o que as bibliotecas podem fazer, para favorecer a integração dessas pessoas, a autora citada relaciona entre os serviços principais a serem dispensados a "acolhida".

E o queé uma boa acolhida para uma pessoa que utiliza uma biblioteca, consultando obras ou solicitando serviços, principalmente por intermédio do espaço digital? Ser acolhido, neste contexto, significa poder utilizar os mesmos serviços que são disponibilizados aos o utros usuários, e o sinal de boas-vindas a esses serviços, para as pessoas com limitações oriundas de deficiência, érepresentado pela presençade um dos selos de acessibilidade, como o Bobby A pproved ou o W3C -WA I, anteriormente apresentados na página institucional da biblioteca, que édisponibilizadanal nternet.

Parafraseando as palavras de M azzoni et alii (2001), se oferecemos condições de acessibilidadeàs pessoas portadoras de deficiência, nós as encontraremosao nosso lado, nas salas de aula e nas bibliotecas. C aso contrário, se essas condições não forem oferecidas, elas precisarão chegar até às informações, procurando-as pelo mundo digital. E essemundo digital éum espaço em expansão, 0 espaço digital, que se estende por vários outros níveis, além dos sítios web dal nternet. C onformeB lattmann \& Alves (1999):

"T endo atecnologia da informação como pano defundo, os acervos de bibliotecas evoluíram no quese refere aos suportes dainformação do papel, passando pelas bases de dados ( cd-rom, acesso arede decomputadores paradados compartilhados, acesso via rede) e pelo acesso à informação hipermídia disponível on-line (qual quer lugar a qualquer tempo)."

A percepção da existência do espaço digital tem sido registrada por vários autores. Rodrigues (1996) analisa como a inércia apontada por D e L as H eras (2000) está presenteno setor de documentação eintui a necessidade deque esse espaço seja mais bem explorado:

"A téagora, os documentos digitais pouco mais têm sido do que réplicas (versões ampliadas e melhoradas) dos livros e outros documentos tradicionais em papel. É previsível que o recurso sistemático à edição eletrônica e aos suportes digitais provoque uma mudança de paradigmaeo aparecimento denovos tipos dedocumentos, sem qualquer correspondência com os existentes em suportes tradicionais. Por outro lado, a conjugação desta tendência com a distribuição em rede poderesultar no aparecimento denovos produtos/serviços [...]."

O bserva-se, portanto, queo espaço digital jáestá incorporado às atividades das bibliotecas bem equipadas, sendo a essência das bibliotecas virtuais e sendo, por outro lado, indispensável para muitas das atividades das bibliotecas com sedefísica.

O espaço digital passou, assim, a ser a viamais transitável por todas as pessoas que procuram informações e dispõem de acesso àl nternet eaos computadores. E este pode ser um espaço mais socialmenteinclusivo, caso ofereça acessibilidadea todos, respeitando suas capacidades elimitações.

A s bibliotecas devem cuidar para que seja permitida a participação de todos os seus usuários, aos serviços que disponibiliza, usando para tanto mídias alternativas de suporteàinformação quesejam compatíveis àquelas com as quais os usuários af etados por deficiência estão familiarizados ater contato com as informações. I sso seaplica, observando, inicial mente, quais são as incapacidades que as pessoas apresentam (por exemplo: para ler em tinta, para ler em Braille, para ouvir, parafalar, para manipular objetos etc.) paraqueem seguida seja encontrada uma forma de disponibilizar a informação, na qual as capacidades que as pessoas p ossuem possam ser desempenhadas e o objetivo original de obter à informação desejada sejaal cançado. 


\section{A acessibilidade à informação no espaço digital}

Esseobjetivo seconcretizapelo uso combinado deajudas técnicas com conteúdos digitais acessíveis. Faz-se necessária, também, a existência de um suporte adequado a esses usuários, tanto para a utilização das ajudas técnicas, quanto na preparação de materiais alternativos, tais como a digitalização de textos disponíveis apenas em impresso, atranscrição em texto dedocumentos oraisea descrição de documentos visuais.

\section{CONSIDERAÇÕES FIN AIS}

0 espaço digital permite a realização do novo, sendo possível oferecer um atendimento muito mais amplo à informação, que pode ser exibida em toda a sua riqueza, apresentada de diferentes formas. É importante que esta possibilidade seja utilizada para se garantir a acessibilidade aos conteúdos, atendendo-se, assim, atodas as características das pessoas, tanto em suas limitações quanto em suas preferências.

A acessibilidade digital deve ser considerada como um requisito para toda atualização que se faça nos sistemas de informação e documentação utilizados pelas bibliotecas, como também nas ocasiões em que se amplia o acervo, com títulos multimídia, ese adquirem novos produtos eequipamentos.

A rtigo aceito para publicação em 18-11-2002

\section{REFERÊNCIAS}

BLA TTM A N N , U .; A LVES, M . B. M . O rganizações virtuais da informação. D isponível em : < http:// www.geocities.com/ublattmann/ papers/orgvirt1.html> . A cesso em: 20 jun. 2002.

CANGU ILHEM , Georges. 0 normal eo patológico. Rio de Janeiro: Forense U niversitária, 1995

DE LAS HERAS, A R. Las propiedades del espacio digital. In: CON GRESO IBERO LATIN O AMERICANO DE IN FORMÁTICA EDU CATIVA ESPECIAL, 2. 2000, Córdoba. Anais ... Córdoba : [s. n.], 2000. 1 CD-ROM

ECH EVERRIA, J avier .I mpacto social y linguístico delasnuevastecnologías dela información y las comunicaciones I $\mathrm{n}$ : TRO IS espaces linguistiques face aux défis de la mondialisation. Paris : [s. n.], 2001.

J A I IK, Sophie. Place aux personnes handicapées dans nos bi bli otèques. Q uebéc : O ffice des Personnes $\mathrm{H}$ andicapées du Q uebec, 1997.

M A ZZO N I, A . A . et al. A spectos queinterferem na construção da acessibilidade em bibliotecas universitárias. C iência da I nformaçãa, Brasília, v. 30, n. 2, p. 29-34, 2001.

M A ZZO N I, A Iberto A; TO RRES, Elisabeth F. Tecnologia para apoio à diversidade. D isponível em: < http://iee.inf.ufsc.br>. A cesso em: 24 maio 2001.

RO D RIGU ES, Eloy. As bibliotecas na era digital. Boletim Barata, M inho, n. 38, maio 1996. D isponível em: < http:// www.bib.eng.uminho.pt/Pessoal/Eloy/barata.htm>. A cesso em: 21 jun. 2002.

RO M A Ñ ACH , J avier Sociedad dela información para todos. Disponível em: < http://www.sidar.org/docus/sit.doc.>. A cesso em: 12 jul 2002.

SA N C H EZ M O N TO YA, Rafael. O rdenador y discapacidad. M adri : EPE, 1999 .

W 3C : recomendações para acessibilidade em páginas web. D isponível em: <http://www.w3.org/TR/WAI-WEBCONTENT>. 